\title{
Percutaneous Management of Malignant Biliary Strictures: Current Status and Future Directions
}

\author{
Mohammed Attaya, MD ${ }^{1} \quad$ Hosam Attaya, MD ${ }^{1} \quad$ Ashraf Thabet, MD ${ }^{1}$ \\ ${ }^{1}$ Division of Interventional Radiology, Department of Radiology, \\ Massachusetts General Hospital, Harvard Medical School, Boston, \\ Massachusetts \\ Address for correspondence Ashraf Thabet, MD, Division of \\ Interventional Radiology, Department of Radiology, Massachusetts \\ General Hospital, Harvard Medical School, 55 Fruit Street, GRB 298, \\ Boston, MA 02114 (e-mail: athabet@mgh.harvard.edu).
}

Dig Dis Interv 2017;1:36-46.

\author{
Abstract \\ Keywords \\ - malignant biliary \\ obstruction \\ - percutaneous \\ interventions \\ - biliary drainage \\ - biliary stents
}

\begin{abstract}
Various minimally invasive percutaneous interventions may be performed for the treatment and management of malignant biliary obstruction. The types of percutaneous interventions include percutaneous transhepatic biliary drainage, percutaneous cholecystostomy, and biliary stent placement. Biliary stents have undergone continued evolution in design to prolong patency, increase cost-effectiveness, improve patient survival, and quality of life. Furthermore, investigational techniques such as radiofrequency ablation, intraluminal brachytherapy, and photodynamic therapy promise new technologies in the field of biliary intervention. This review focuses on the current status of percutaneous therapies for malignant biliary strictures and obstruction.
\end{abstract}

Biliary obstruction manifests as abnormal luminal narrowing of the biliary tree, which impedes the normal physiologic flow of bile to the small bowel. The etiology of biliary obstruction is often divided into benign and malignant causes, which may be difficult to distinguish at presentation but is nonetheless imperative to guide management and determine prognosis. Patients with benign biliary obstruction often have a good prognosis and do well after intervention while those with malignant biliary obstruction (MBO) often present at a later stage and have a poor prognosis.

Although the clinical incidence of neoplasms that cause $\mathrm{MBO}$ is relatively low, there has been increasing incidence by estimates from the Surveillance, Epidemiology, and End Results database from North America. ${ }^{1}$ Malignant biliary obstructions are caused by either external compression or infiltration of the biliary tree by the tumor. The most common malignancies that cause MBO are cholangiocarcinoma and adenocarcinoma of the pancreas, but gallbladder, gastric, and ampullary/duodenal malignancies in addition to lymphoma, intrahepatic metastasis, and metastatic lymphadenopathy may also be causative.

Clinical presentation of MBO is dependent upon the etiology. Patients with intrahepatic cholangiocarcinoma often present with abdominal pain, night sweats, and cachexia.
Those with extrahepatic or distal tumors often present with obstructive symptoms of jaundice or pruritus. In fact, obstructive jaundice is the most common clinical presentation and chief presenting symptom in $70 \%$ of patients with pancreatic cancer at the time of diagnosis. ${ }^{2}$ Untreated MBO may also cause cholangitis or sepsis due to increased bowel wall permeability, portal system bacteremia, and impaired liver T-lymphocyte function. ${ }^{3,4}$

The management of patients with $\mathrm{MBO}$ usually requires a multidisciplinary approach within tertiary care centers. Clinical expertise from oncologists, hepatologists/gastroenterologist, hepatobiliary surgeons, radiologists, interventional radiologists, and radiation oncologists is necessary for successful treatment. Interventional radiologists may be asked to provide percutaneous biliary decompression for palliation or preoperative drainage in those with resectable disease..$^{5-7}$ Klatskin's initial observation that patients with cholangiocarcinoma die from biliary obstruction rather than metastatic disease still holds true and local tumor control is important for patient survival. ${ }^{8}$ Though biliary decompression may not improve survival, palliative therapy reduces the risk of sepsis, improves the liver function that is a prerequisite for initiation of chemotherapy, resolves jaundice, and decreases pain. received

November 15, 2016 accepted after revision

February 10, 2017

published online

March 30, 2017
Issue Theme Biliary Diseases and Interventions; Guest Editor, Ronald S. Arellano, MD
Copyright $\odot 2017$ by Thieme Medical Publishers, Inc., 333 Seventh Avenue, New York, NY 10001, USA Tel: +1(212) 584-4662.
Dol https://doi.org/ 10.1055/s-0037-1601378. ISSN 2472-8721. 
Herein, we review the role of interventional radiology in the treatment and management of patients with malignant biliary obstruction.

\section{Role of Diagnostic Radiology}

Ultrasound (US) is an invaluable diagnostic modality for the initial assessment of patients with suspected hepatobiliary pathology. Real-time US imaging allows assessment of the hepatic parenchyma and biliary tree, presence of ascites, and biliary confluence patency. Evaluation of the distal common bile duct, however, is often limited such that additional evaluation usually requires cross-sectional imaging with computed tomography (CT), magnetic resonance imaging (MRI), and/or magnetic resonance cholangiopancreatography. These imaging modalities help determine the cause of biliary obstruction and define the extent of disease, level of obstruction, and biliary anatomy. Ultrasound and CT may also be used for histopathologic confirmation by either interventional radiology (US- or CT-guided biopsy) or endoscopically using endoscopic retrograde pancreatography (ERCP) or endoscopic US-guided fine needle aspiration. Positron emission tomography/CT has a role in detecting distant and nodal metastasis although its use in the diagnosis of cholangiocarcinoma is not well established.

\section{Percutaneous Techniques}

There have been multiple advances in radiology and percutaneous intervention since Burckhardt and Muller performed the first radiologic visualization of the biliary tree by puncture of the gallbladder in $1921 .^{9}$ The first percutaneous transhepatic cholangiography (PTC) was performed by Huard et $\mathrm{al}^{10} 16$ years later. Despite the use of multiple methodologies and techniques, it was not until the use of the fine needle technique developed at Chiba University and presented by Oto et al that resulted in a significantly decreased complication rate. ${ }^{11}$ These advances ultimately shifted palliative therapy from surgery to percutaneous or endoscopically placed stents. Similarly, stents have undergone a significant evolution in design from plastic to bare metallic to covered metallic and ultimately to drug-eluting stents. Stent evolution is driven by the desire to maintain stent patency, decrease tumor ingrowth, and increase procedure cost effectiveness. ${ }^{12,13}$ Moreover, aside from percutaneous stent placement, minimally invasive palliative therapy has also been performed with intraluminal brachytherapy, endoluminal biliary radiofrequency ablation (RFA), and photodynamic therapy (PDT).

\section{Percutaneous Transhepatic Biliary Drainage}

For patients who will undergo surgical excision of an obstructing mass, preoperative biliary decompression may provide normalization of liver enzymes and bilirubin levels while limiting the risk of ascending cholangitis. Access for percutaneous transhepatic biliary drainage (PTBD) may be from the right or left liver lobes depending upon the extent of biliary obstruction. Once access to the biliary system is obtained with a needle (e.g., Chiba), a cholangiogram defines the biliary anatomy and characterizes the obstruction. A hydrophilic guide wire is placed across the stricture, the tract is dilated, and an internal-external drainage catheter is positioned across the stricture (i.e., the tip of the catheter in the bowel). If initial attempts to cross a stricture fail, an external-only drain may be left in place to reduce inflammation and decompress the biliary so that reattempt at internalization may be successful. A PTBD may be technically limited secondary to nondistention of the biliary system, but interestingly there is no difference in success rates between dilated and nondilated biliary systems. ${ }^{14,15}$

\section{Percutaneous Cholecystostomy}

Percutaneous cholecystostomy is usually performed for decompressing an inflamed gallbladder in a patient who cannot undergo surgery at the time of presentation. Percutaneous cholecystostomy may also be performed as an alternative to PTBD when the biliary ducts are not adequately dilated. This may be performed via a transhepatic or transperitoneal approach. In the transhepatic approach, the drainage catheter traverses a portion of the liver before entering the gallbladder; this provides catheter support and decreased risk of an intraperitoneal biliary leak. In the transperitoneal approach, the gallbladder is punctured directly. Trocar or Seldinger approaches may be utilized for both techniques. Catheters are usually kept in place for 2 to 3 weeks to allow for tract maturation. Access through the gallbladder may be used to treat MBO via stent placement. ${ }^{16,17}$ Complications may include catheter dislodgement, pain, bleeding, pneumothorax, fistula formation, or biliary peritonitis.

\section{Biopsy}

If the diagnosis or etiology of an MBO remains unclear with cross-sectional imaging, tissue collection utilizing brush cytology or forceps biopsy can provide a definitive diagnosis. Brush cytology is typically performed during ERCP and is considered safer and technically easier than a forceps biopsy. Several studies have attempted to quantify the sensitivity of each technique. One study in which brush cytology was performed during percutaneous biliary drainage demonstrated sensitivity, specificity, positive predictive value, negative predictive value, and accuracy of $75,100,100,12.5$, and $75.9 \%$, respectively. ${ }^{18}$ The sensitivity of brush biopsy in the diagnosis of cholangiocarcinoma was greater than in those with noncholangiocarcinoma. ${ }^{18}$ Forceps biopsy is unique in that unlike brush cytology, it provides a sample of the subepithelial stroma (-Fig. 1). In a published series of 130 patients with MBO who underwent forceps biopsy after PTBD, the sensitivity, specificity, and accuracy were $78.4,100$, and $79.2 \%$, respectively. ${ }^{19}$ In another published series, forceps biopsy was found to have a sensitivity of $71 \%{ }^{20} \mathrm{~A}$ study comparing brush cytology with clamshell forceps under choledochoscopic guidance and clamshell forceps found that utilization of clamshell forceps with cholangioscopy was more sensitive than the other 

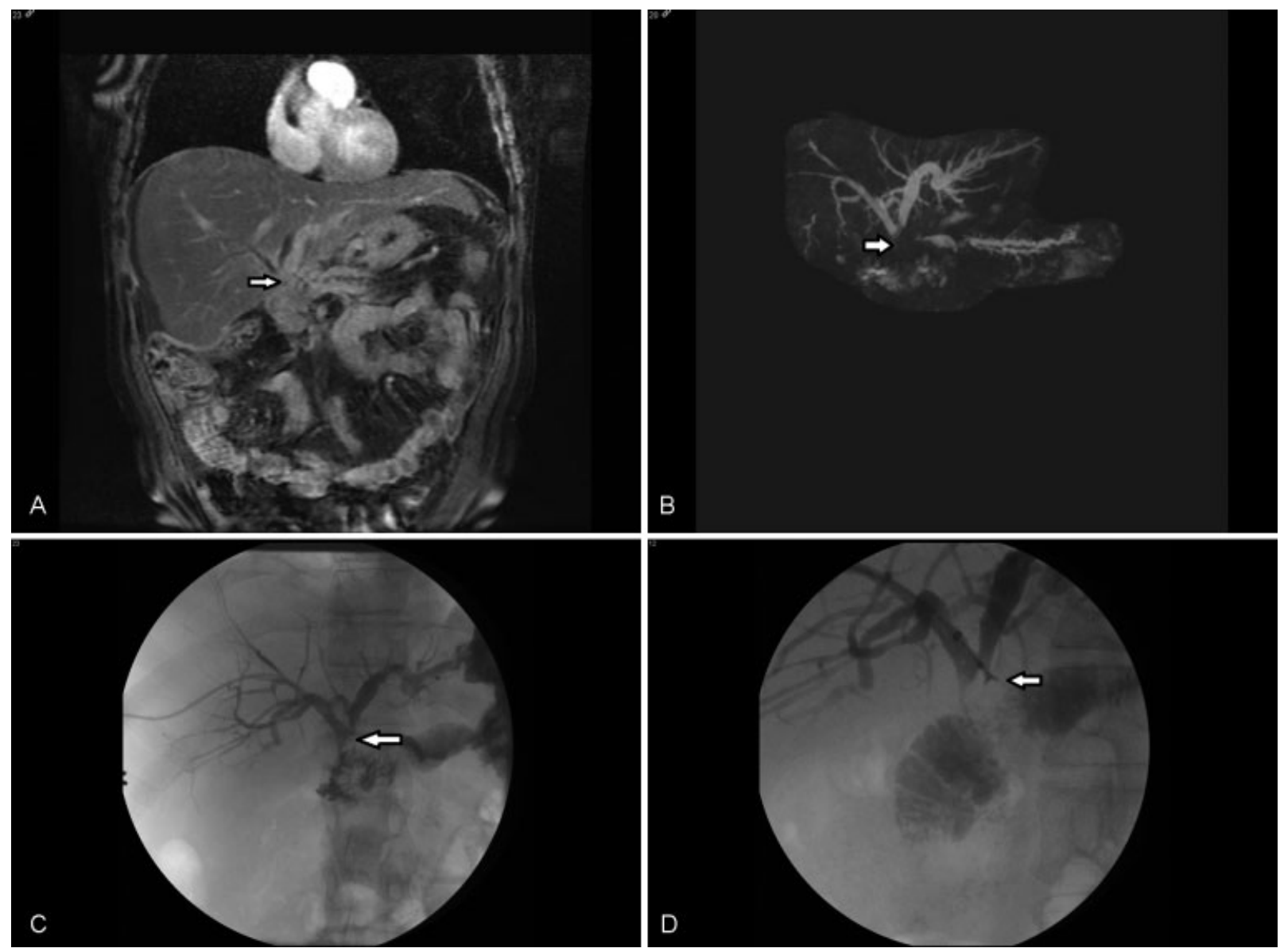

Fig. 1 A 74-year-old woman presents with recurrent cholangitis. (A) Coronal gadolinium-enhanced T1-weighted fat-saturated image demonstrates illdefined stricture at the level of the hilum (arrow) with intrahepatic ductal dilatation. (B) Coronal T2-weighted MR cholangiopancreatography image demonstrates abrupt cutoff of both right and left intrahepatic ducts (arrow). (C) Percutaneous transhepatic cholangiography demonstrates severe narrowing of the common bile duct (arrow). (D) Biopsies were taken using a forceps device (arrow). MR, magnetic resonance.

two techniques but was not statistically significant. ${ }^{21} \mathrm{~A}$ more recent study comparing brush cytology versus forceps biopsy found sensitivity, specificity, and accuracy for brush cytology versus forceps biopsy were $47.8,100,69.2 \%$, and $92.1,100$, $93.6 \%$, respectively. ${ }^{22}$ A study comparing forceps biopsy versus a modified cytology sampling in which cytological sampling was obtained by washing the forceps device in cytological solution demonstrated sensitivity for forceps biopsy and forceps wash cytology of 78 and $61 \%$, respectively. ${ }^{23} \mathrm{Kim}$ et al have found that the addition of bile cytology from forceps biopsy can increase sensitivity and may be a complementary diagnostic tool for diagnosing cholangiocarcinoma. In their retrospective series of both endoscopic and percutaneous intervention which included 766 patients sensitivity for bile cytology, forceps biopsy, and utilization of both was $24.7,74.4$, and $77.9 \%$, respectively. ${ }^{24}$

\section{Portal Vein Embolization}

In patients undergoing hepatectomy, portal vein embolization (PVE) may be performed as an adjunct to induce compensatory enlargement of the liver remnant. ${ }^{25} \mathrm{Hem}$ ming et al demonstrated that in those patients in whom liver resection would ultimately result in future liver remnant volume of less than $25 \%$, PVE was not associated with pre- or postoperative complications. Moreover, patients who did not receive PVE had longer hospital stays and had a higher incidence of hepatic failure. Uhl et al noted that PVE of portal vein segmental branches 4-8 resulted in average volume increase in segments 2 and $3280 \pm 95 \mathrm{~mL}$ to $420 \pm 98 \mathrm{~mL}$ within 6 weeks. ${ }^{26}$

\section{Plastic versus Metallic Stent}

Plastic stents were the first type of stents developed for the treatment of MBO but were problematic due to their small size of $12 \mathrm{~F}$ (the maximum size that could fit through the endoscope) or $14 \mathrm{~F}$ when placed percutaneously, and propensity for occlusion. Moreover, the supplemental addition of antibiotics and/or ursodeoxycholic acid has not been shown to increase stent patency. ${ }^{27}$ Self-expandable bare metallic stents (SEMS), capable of expansion to $30 \mathrm{~F}$, were developed to overcome these problems ( - Fig. 2). Multiple studies have demonstrated that SEMS provide significantly longer patency periods than plastic stents. ${ }^{28-32}$ Moreover, the superiority of SEMS compared with plastic stents have been further supported by meta-analyses and randomized clinical trials. ${ }^{33-35}$ 

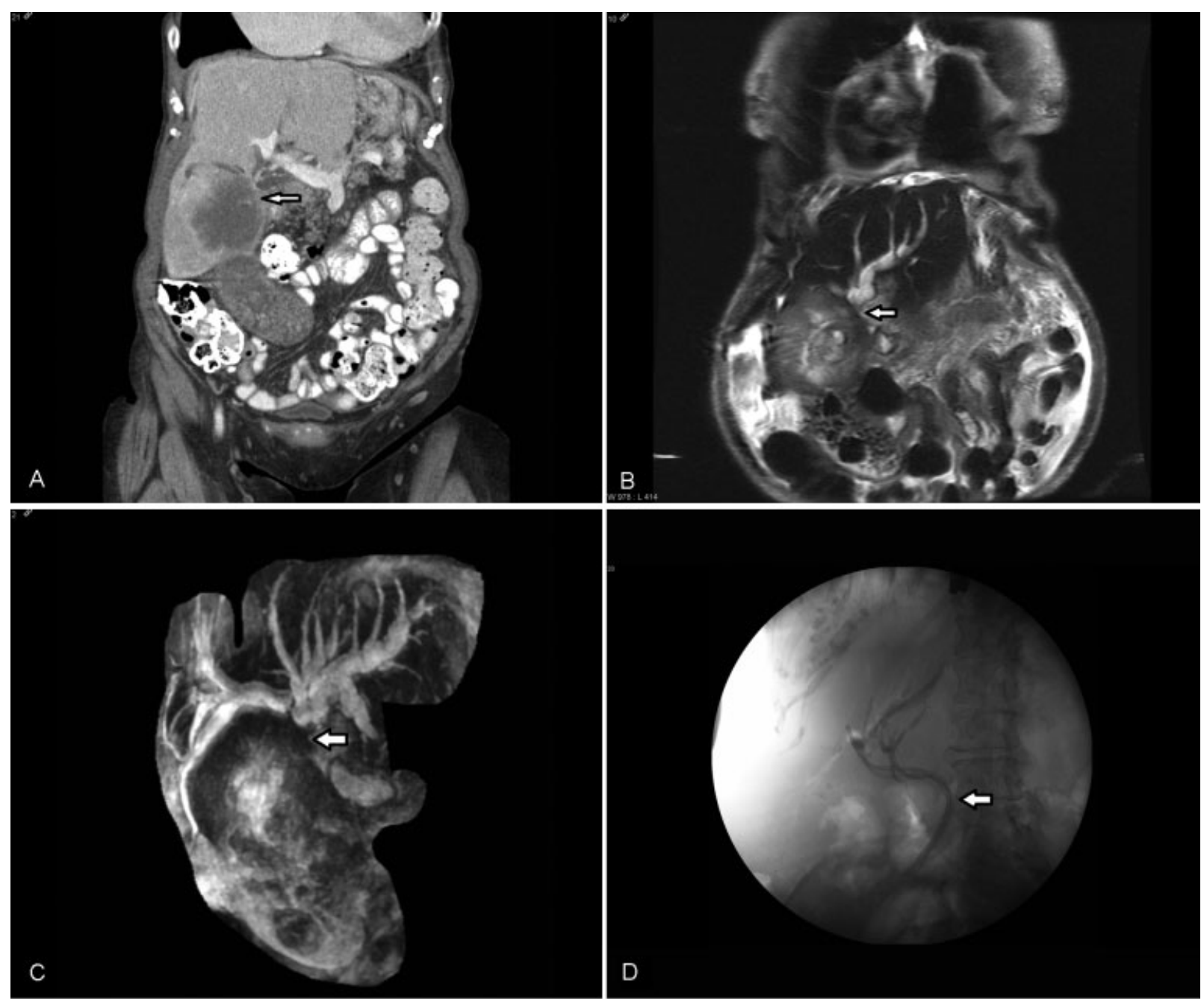

Fig. 2 An 82-year-old female patient chronic thrombocytopenia, mechanical mitral valve replacement, atrial fibrillation on warfarin presenting with abdominal pain and elevated liver function tests. (A) Coronal gadolinium-enhanced CT in portal venous phase reveals a large gallbladder adenocarcinoma extending into and involving liver segment 5 with associated common bile duct narrowing and intrahepatic ductal dilatation (arrow). (B) Coronal T2weighted single shot fast spin echo MR image demonstrates gallbladder mass obstructing the left hepatic bile duct system (arrow). (C) 3D reconstructed MR cholangiopancreatography images revealing common bile duct obstruction due to gallbladder lesion (arrow). (D) Self-expandable metal stents were inserted endoscopically (arrow). 3D, three-dimensional; CT, computed tomography; MR, magnetic resonance.

SEMS are made from either stainless steel (cobalt-chromium) or nitinol (nickel-titanium) mesh that allows the stent to embed into the biliary wall, thereby decreasing the risk of migration. The disadvantage to SEMS, however, is that the mesh-like structure of the stent may result in neoplastic tissue in-growth and ultimately occlusion. The combination of tumor ingrowth, epithelial hyperplasia, biofilm deposition, and sludge limits the median patency to 120 days. ${ }^{36}$ Occlusion of SEMS ranges from 20 to $50 \%{ }^{28,31,37}$ Another disadvantage of SEMS is that they are not removable or interchangeable and therefore must be utilized in the appropriate clinical scenario. Self-expandable metal stents are, however, much less expensive than covered SEMS.

\section{Covered Biliary Stents}

Covered SEMS (CSEMS) are similar to SEMS in their tubular design but are covered by a thin membrane that theoretically prohibits tumor in-growth (-Fig. 3 ). Since CSEMS are not embedded in the biliary wall, they are removable but also prone to migration. Because CSEMS are removable, some advocate their use when the histological diagnosis is unclear while uncovered SEMS should be used for confirmed malignancy. Multiple antimigrational covered stents have also been developed. Isayama et al described a modified Zeo stent with flared ends which effectively, though not completely, prevented stent migration. ${ }^{38} \mathrm{~A}$ randomized trial with 120 patients showed an increased stent patency with antimigration covered stent compared to uncovered stents (187 vs. 132 days). ${ }^{39}$

Published studies demonstrate conflicting evidence as to whether CSEMS increase stent patency. A meta-analysis by Saleem et al found that CSEMS had longer stent patency times significantly as compared with uncovered stents. ${ }^{40} \mathrm{~A}$ more recent meta-analysis, however, showed no difference in patency periods between the two types of stents. ${ }^{41}$ Randomized trials have shown no difference in stent patency or patient survival between the two groups. ${ }^{42,43}$ 


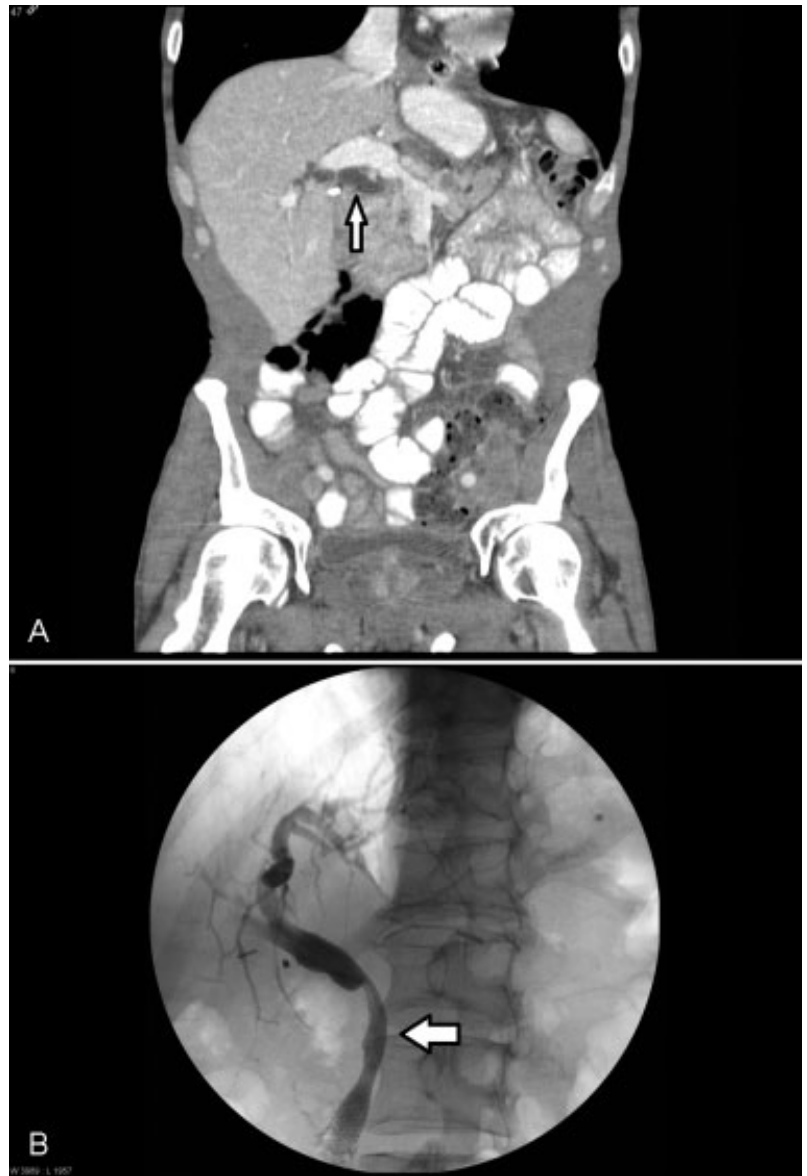

Fig. 3 A 57-year-old male patient with, history of esophageal cancer, presents with jaundice and abdominal pain. (A) Coronal contrastenhanced $C T$ in portal venous phase demonstrates intrahepatic duct dilatation at the level of the porta hepatitis (arrow) due to a malignant stricture. (B) Percutaneous transhepatic cholangiography with the placement of a $10 \mathrm{~mm} \times 6 \mathrm{~cm}$ covered metal stent (arrow).

The catheter delivery system of the CSEMS is larger than SEMS. A measuring pigtail may be used for accurate deployment of the covered stent to minimize the risk of blocking the cystic duct. The covering membrane can be made of multiple materials including polyurethane, silicone, or expandedpolytetrafluoroethylene/fluorinated ethylene propylene (ePTFE/FEP). Polyurethane covered stents have shown limited efficacy in prolonging stent patency compared with uncovered SEMS. ${ }^{44-46}$ ePTFE/FEP covered stents seem to be effective in providing biliary drainage. ${ }^{47-49}$ Disruption of the polymer cover can occur either through mechanical damage related to stent microfracture during placement or through a chemical process. Chemical degradation can occur by exposure to bile, acidic gastric contents, and/or pancreatic enzymes. ${ }^{50}$ Decreased porosity of ePTFE/FEP grafts has been shown to decrease the incidence of stent occlusion and sludge incrustation. ${ }^{47-49}$

\section{Drug-Eluting Stents}

Drug-eluting stents (DES) may be an alternate treatment modality for MBO in the future. Currently, there are few published studies regarding DES. Mezawa et al described the use of a carboplatin biliary drainage tube in five patients with inoperable cholangiocarcinoma and reported the DES was well tolerated and had an efficacy of $60 \%{ }^{51}$ Suk et al published the first biliary study of paclitaxel-DES in humans concluding that DES are effective, safe, and technically feasible. ${ }^{52}$ Song et al published a prospective randomized trial comparing paclitaxel-DES to control CSEMS in patients with MBOin 49 patients and found that DES provided no advantage regarding stent patency or patient survival compared with the control group. ${ }^{53}$ Stent in-growth occurred in $5 / 24$ patients in the DES group compared with $4 / 25$ in the control group. Much research and higher powered studies are necessary to determine the potential advantages of DES over conventional covered stents.

\section{T, Y, and X (Crisscross) Configured Stents}

Malignant hilar obstruction is most commonly caused by cholangiocarcinoma and can be difficult to treat. Cholangiocarcinoma occurs at the confluence of the left and right hepatic ducts in 60 to $70 \%$ of the cases, distal common bile duct in 20 to $30 \%$ of the cases, and intrahepatic ducts in 5 to $10 \%$ of the cases. ${ }^{54}$ In 1975 , Bismuth and Corlette classified malignant hilar stenosis into four categories based on the extent of involvement of the common hepatic, left, and right bile duct. ${ }^{55}$ Type I obstruction involves the common hepatic duct (CHD) with preservation of the confluence. Type II obstruction involves the CHD as well as the confluence of the left and right ducts. Type IIIA obstructions involve the CHD and right hepatic duct at the confluence and type IIIB involve the CHD and left duct. Type IV injuries extend to the bifurcations of the left and right hepatic ducts. Percutaneous or endoscopic intervention is the mainstay of palliative treatment as only 20 to $30 \%$ of tumors are resectable. ${ }^{56}$

Controversies exist as to whether partial/unilobar or total/bilobar/bilateral drainage should be performed for palliative therapy. Advocates of partial/unilateral drainage emphasize lower complication rates associated with a minimally invasive approach. ${ }^{57}$ Some investigators call for complete drainage ${ }^{58}$ while others still advocate for a stepwise approach (i.e., placement of a single stent and assess for clinical response, then place a second stent if necessary). ${ }^{59}$ Others advocate for unilobar drainage in Bismuth I-III obstructions and bilobar drainage in type IV obstruction. ${ }^{60}$ Regardless, bilateral biliary drainage may be beneficial in some patients to prevent cholangitis, preserve liver function, and has been associated with better survival rates. ${ }^{61}$ Multiple stents and techniques have been developed for the bilateral palliative treatment of malignant hilar obstruction.

Currently, two techniques have been developed for percutaneous placement of bilateral SEMS, including the side-byside (SBS) and stent-in-stent (SIS) deployment techniques (-Fig. 4). SBS technique results in deployments of SEMS in a parallel configuration. This configuration may prevent full expansion or result in the collapse of one or both stents. Interestingly, an endoscopic series comparing the SBS to SIS techniques demonstrated that the complication rates were 

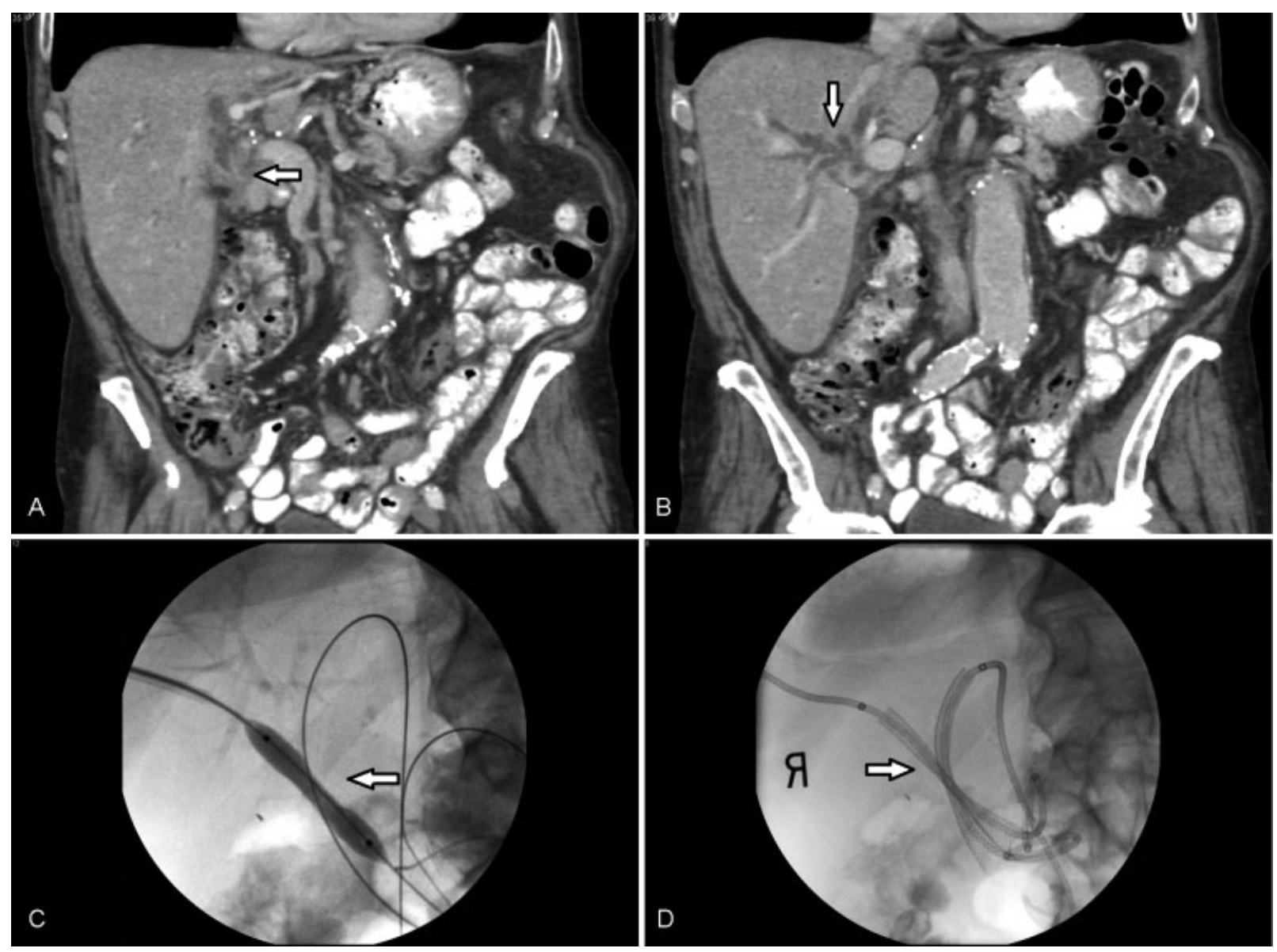

Fig. 4 A 77-year-old male patient presents with jaundice, malaise, fatigue, and a $15 \mathrm{lb}$ weight loss over 2 weeks. (A) Coronal gadoliniumenhanced CT in portal venous phase demonstrates smooth narrowing with some enhancement of the common bile duct at anastomosis (arrow), upstream dilatation of CBD, and intrahepatic biliary duct consistent with anastomotic stenosis due to bile duct adenocarcinoma. (B) Coronal gadolinium-enhanced CT in portal venous phase demonstrates upstream dilatation of CBD and intrahepatic biliary ducts (arrow). (C) Balloon dilatation of the malignant stricture (arrow) with a noncompliant $8 \mathrm{~mm}$ balloon. (D) Two crisscrossing (arrow) $10 \mathrm{~mm} \times 6.8 \mathrm{~cm}$ covered metal biliary stents were placed via a percutaneous approach. CT, computed tomography.

higher in SBS deployment; however, SBS tends is associated with higher patency rates. ${ }^{62}$ In the SIS technique, a stent is deployed through the mesh of the first stent. This may prevent stent displacement. ${ }^{63}$ Open cell designs have been developed to overcome the technical difficulties of SIS deployment and allow easier connectivity between stents as opposed to the traditional closed cell designs. Both techniques may be utilized for T-configured or Y-configured stents.

Y-stents are composed of two components, including the main frame and a long contralateral limb stent. The main piece consists of a common bile duct (CBD) section (uncovered), a covered long limb, and a covered short limb. A secondary covered stent is later mated to the short limb creating the full "Y" configuration (-Fig. 5). In a prospective pilot study including 20 patients, Gwon et al demonstrated that ePTFE covered Y-configured stents (ComVi stent; TaeWoong Medical, Seoul, Korea) are safe and clinically effective in the palliative treatment of hilar biliary obstruction. ${ }^{64}$ There were minor complications of self-limiting hemobilia in one patient and rapidly resolving cholangitis in three patients. Similar outcomes have been demonstrated with silicone covered nitinol Y-configured stents (EGIS Biliary KEY stent; S\&G Bio, Seoul,
Korea $)^{65}$ and self-expandable nitinol stents (8.5F, Niti-S Biliary Y-type, Taewoong Medical) ${ }^{66}$ Generally, complication rates during Y-configured stent placement are low with the technical success achieved in most cases.

The transhepatic or T-configured stents have also been used with success. The T-configured stents have a horizontal stent that bridges the right and left hepatic ducts and a vertical component that extends into the common bile duct. T-configured stents have been made with multiple grafts or membranes. No study has demonstrated superiority between $\mathrm{Y}$ - and T-configured stents, but some authors believe that T-configured stents may have some advantages. Kim et al argue that $\mathrm{T}$-configuration offers a large luminal diameter throughout the biliary system which can be placed through a single access, is safe, and reliable. Also, overlapping endoprostheses may prevent stent migration. ${ }^{63}$

In certain situations, hilar malignancy may extend beyond segmental ducts causing multiple intrahepatic obstructions in which $\mathrm{T}$ - and $\mathrm{Y}$ - configured stents may not provide adequate drainage. In such instances, crisscrossing or $\mathrm{X}$ configured stents may be beneficial ( - Fig. 4). This entails crossing stents to drain two right sector ducts and a left 

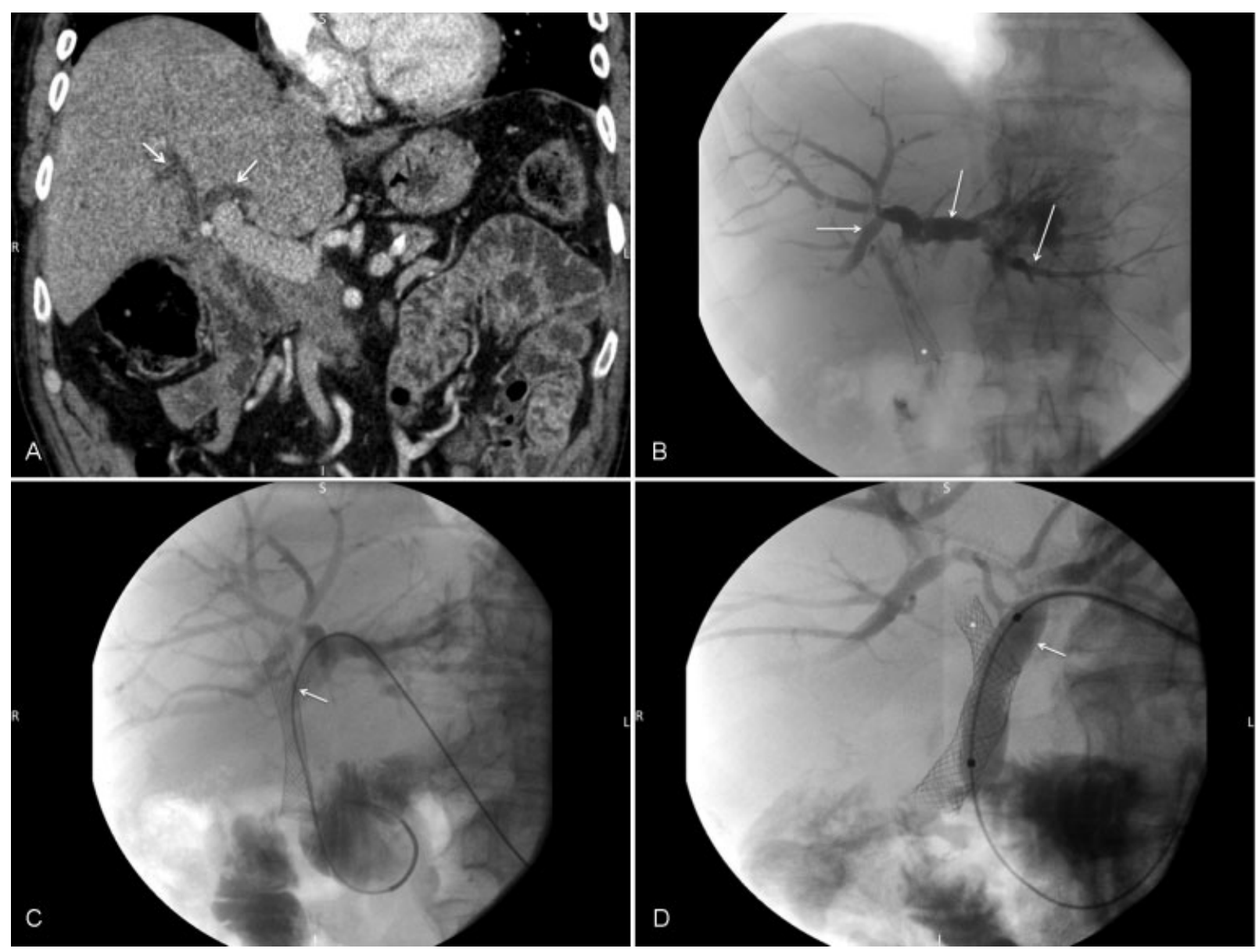

Fig. 5 (A) Contrast material-enhanced coronal CT scan in a patient who is s/p Whipple procedure for adenocarcinoma of the pancreas. White arrows point to dilated left and right bile ducts. (B) Percutaneous transhepatic cholangiogram that demonstrates a metal stent with the right hepatic duct (white asterisk) and dilates intrahepatic bile ducts (white arrows). (C) Image from percutaneous cholangiogram that demonstrates a guidewire and catheter that was placed into the biliary stent and the bowel. (D) The fluoroscopic image that demonstrates $10 \mathrm{~mm}$ balloon (white arrow) distention of metal stent (asterisk). (E) The fluoroscopic image that demonstrates new metal stent (white arrow) in the left biliary tree that has been placed through an existing right-sided biliary stent. (F) Contrast material-enhanced coronal CT scan in a patient who is s/p Whipple procedure for adenocarcinoma of the pancreas and percutaneous biliary stent placement in a Y-configuration. White arrows point to metal stents within the left and right bile ducts. CT, computed tomography.

hepatic duct for trisectoral drainage. Placement of the stent depends on the biliary anatomy. If standard anatomy exists, a stent may be placed in the right anterior duct to the left hepatic duct and another stent from the right posterior duct to the common bile duct. Bae et al have demonstrated that this configuration is feasible, safe, and effective. ${ }^{67}$ A downside to $\mathrm{X}$-configured stents is that they may require multiple hepatic access points. At present, $\mathrm{X}$-configured seems to be noninferior to T- and Y-configured stents; however, further investigation is needed to determine if trisectoral drainage provides durability over other methods.

\section{Intraluminal Brachytherapy}

Intraluminal brachytherapy (ILBT) aims to treat malignant obstruction by the insertion of radioactive implants or pellets directly into tissue, minimizing radiation risk to adjacent organs. ${ }^{68,69}$ ILBT is most commonly used for the treatment of localized prostate cancer but recently has also been used for inoperable biliary malignancies. Iridium-192 is a gamma emitter, which has produced promising results for the treatment of inoperable biliary tumors. Published studies have demonstrated that ILBT is safe and technically feasible without major complications and positive impact on the quality of life. ${ }^{70,71}$ Moreover, the combination of percutaneous stenting and ILBT has been described. Eschelman et al reported on a series of 22 patients with unresectable biliary obstruction caused by either cholangiocarcinoma or secondary extrahepatic bile duct malignant tumors who underwent stenting and radiation therapy (average $25 \mathrm{~Gy}$ ), including ILBT with Ir-192 and found increased stent patency and survival in the cholangiocarcinoma group. ${ }^{72}$ Conversely, Takamura et al described a multimodality approach (ILBT, external beam radiation therapy, and biliary stenting) that did not impact survival or biliary patency in 93 patients but improved the quality of life in those with extrahepatic bile duct carcinoma. ${ }^{73}$ Similarly, Isayama et al found that external beam radiotherapy improved patient prognosis and patency of SEMS but ILBT provided no additional benefit. ${ }^{74}$ Patients with inoperable extrahepatic bile duct malignancy who 
underwent EBRT compared with those with EBRT and ILBT had no difference in recurrence rates (53 vs. 36\%) but prolongation of the median time to tumor recurrence 5 versus 9 months. $^{75}$

\section{Radiofrequency Ablation}

Radiofrequency ablation (RFA) is a technique in which rapidly alternating electric current causes vibrational movement of ions, resulting in frictional heat that leads to coagulative necrosis. RFA has been described in primary and secondary hepatic cancers ${ }^{76-78}$ but its novel use for bile duct cancers has not been described until recently. In vivo and ex vivo animal experiments provided the basis upon which the first human use of radiofrequency treatment was performed by Steel et al in 2011 in 22 patients with pancreatic and cholangiocarcinoma. ${ }^{79-81}$ In Steel et al's experimental design, RFA was applied endoscopically before the application of SEMS. It concluded that endobiliary RFA is a safe treatment option; however, its efficacy at providing long-term stent patency remains to be proven in future randomized studies with prolonged follow-up. Mizandari performed the first human application of percutaneous RFA and showed no significant complications with a median survival of 89.5 days and median stent patency of 84.5 days. Only one case of stent obstruction was found 42 days after intervention. ${ }^{82} \mathrm{Li}$ et al demonstrated that stent patency did not significantly differ between RFA and non-RFA groups at 3 months, but stent patency was higher in the RFA group 9/11 (82\%) of patients compared with non-RFA group 5/14 (36\%) patients at 9 months. ${ }^{83}$ In another published series comparing 18 patients who underwent RFA before stent placement to 18 patients who underwent stenting without RFA, the RFA group showed longer median stent patency times 5.8 months compared with control 4.5 months. ${ }^{84}$ There was no significant difference in survival times between both the groups.

Though these novel studies have employed the prophylactic use of RFA to increase stent patency, RFA has also been utilized to obtain repatency once stent occlusion has already occurred. In a prospective study of nine patients with blocked metal stents, all patients had stent patency restored without the use of secondary stents. ${ }^{85}$ Similarly, in a retrospective study of 14 patients with occluded stents, application of intraductal RFA resulted in stent repatency in all patients. ${ }^{86}$

\section{Photodynamic Therapy}

Photodynamic therapy (PDT) is a technique that induces tumor necrosis and apoptosis by free radical induction. PDT has mostly been used for nonmelanotic skin lesions. In 1991 McCaughan et al described its use to treat unresectable cholangiocarcinoma in a patient who survived 4 years after treatment. ${ }^{87}$ In PDT, a systemic photosensitizing agent using a hematoporphyrin derivative or dihematoporphyrin ether is administered to a patient and concentrates within the tissue with rapid turnover such as malignant cells. When exposed to a nonthermal light, a photochemical reaction occurs leading to free radical development. Aside from apoptosis induction, PDT has also been described to have antiangiogenic and immuneinducing effects. ${ }^{88,89}$ Complications include cholangitis and skin photosensitivity reaction. PDT has also been utilized as an adjunct with biliary stenting. The first randomized controlled trial of PDT with and without bile duct stenting showed improvement in bilirubin obstruction after PDT and not stenting alone. ${ }^{90}$ Two subsequent meta-analyses demonstrated that PDT is associated with increased survival benefit, improved biliary drainage and better quality of life. ${ }^{91,92}$ PDT is a safe and promising palliative treatment for cholangiocarcinoma; however, high-powered randomized controlled trials are needed to assess its efficacy further.

\section{Conclusion}

Percutaneous intervention for MBO has exhibited tremendous evolution for treatment and management of $\mathrm{MBO}$. Percutaneous biliary drainage and percutaneous cholecystostomy are foundational techniques for interventional management of MBOs. New stent designs, as well as their unique methods of deployment, have the potential to improve the quality of life of patients. Moreover, investigational techniques such as intraluminal brachytherapy, RFA, and PDT users are exciting new techniques that may extend the frontiers of biliary intervention that may lead to better patient care.

Conflict of Interest

None.

\section{References}

1 Siegel RL, Miller KD, Jemal A. Cancer statistics, 2016. CA Cancer J Clin 2016;66(1):7-30

2 Lillemoe KD, Pitt HA. Palliation. Surgical and otherwise. Cancer 1996;78(3, Suppl):605-614

3 Assimakopoulos SF, Scopa CD, Vagianos CE. Pathophysiology of increased intestinal permeability in obstructive jaundice. World $\mathrm{J}$ Gastroenterol 2007;13(48):6458-6464

4 Katz SC, Ryan K, Ahmed N, et al. Obstructive jaundice expands intrahepatic regulatory $\mathrm{T}$ cells, which impair liver $\mathrm{T}$ lymphocyte function but modulate liver cholestasis and fibrosis. J Immunol 2011;187(3):1150-1156

5 Castaño R, Lopes TL, Alvarez O, Calvo V, Luz LP, Artifon EL. Nitinol biliary stent versus surgery for palliation of distal malignant biliary obstruction. Surg Endosc 2010;24(9):2092-2098

6 Dixon JM, Armstrong CP, Duffy SW, Davies GC. Factors affecting morbidity and mortality after surgery for obstructive jaundice: a review of 373 patients. Gut 1983;24(9):845-852

7 Kloek JJ, van der Gaag NA, Aziz Y, et al. Endoscopic and percutaneous preoperative biliary drainage in patients with suspected hilar cholangiocarcinoma. J Gastrointest Surg 2010;14(1):119-125

8 Klatskin G. Adenocarcinoma of the Hepatic Duct at Its Bifurcation within the Porta Hepatis. An Unusual Tumor with Distinctive Clinical and Pathological Features. Am J Med 1965; 38:241-256

9 Burckhardt H, Muller W. Versuche über die Punktion der Gallenblase und ihre Röntgendarstellung. Deutsche Zeitschrift für Chirurgie 1921;162(3):168-197

10 Huard P, Hop DX. La ponction transhepatique des canaux biliaires. Bull Soc Med Chir Indochine 1937;15:1090-1100 
11 Oto M, Tsuchiya Y, Ono T, Miki M, Saisho H. Application of percutaneous transhepatic cholangiography in internal medicine [in Japanese]. Nihon Rinsho 1969;27(11):2798-2802

12 Boguth L, Tatalovic S, Antonucci F, Heer M, Sulser H, Zollikofer CL. Malignant biliary obstruction: clinical and histopathologic correlation after treatment with self-expanding metal prostheses. Radiology 1994;192(3):669-674

13 Wagner HJ, Knyrim K, Vakil N, Klose KJ. Plastic endoprostheses versus metal stents in the palliative treatment of malignant hilar biliary obstruction. A prospective and randomized trial. Endoscopy 1993;25(3):213-218

14 Kühn JP, Busemann A, Lerch MM, Heidecke CD, Hosten N, Puls R. Percutaneous biliary drainage in patients with nondilated intrahepatic bile ducts compared with patients with dilated intrahepatic bile ducts. AJR Am J Roentgenol 2010;195(4):851-857

15 Weber A, Gaa J, Rosca B, et al. Complications of percutaneous transhepatic biliary drainage in patients with dilated and nondilated intrahepatic bile ducts. Eur J Radiol 2009;72(3):412-417

16 Harding J, Mortimer A, Kelly M, Loveday E. Interval biliary stent placement via percutaneous ultrasound guided cholecystostomy: another approach to palliative treatment in malignant biliary tract obstruction. Cardiovasc Intervent Radiol 2010;33(6):1262-1265

17 Yasumoto T, Yokoyama S, Nagaike K. Percutaneous transcholecystic metallic stent placement for malignant obstruction of the common bile duct: preliminary clinical evaluation. J Vasc Interv Radiol 2010;21(2):252-258

18 Xing GS, Geng JC, Han XW, Dai JH, Wu CY. Endobiliary brush cytology during percutaneous transhepatic cholangiodrainage in patients with obstructive jaundice. Hepatobiliary Pancreat Dis Int 2005;4(1):98-103

19 Jung GS, Huh JD, Lee SU, Han BH, Chang HK, Cho YD. Bile duct: analysis of percutaneous transluminal forceps biopsy in 130 patients suspected of having malignant biliary obstruction. Radiology 2002;224(3):725-730

20 Tsai CC, Mo LR, Chou CY, et al. Percutaneous transhepatic transluminal forceps biopsy in obstructive jaundice. Hepatogastroenterology 1997;44(15):770-773

21 Savader SJ, Prescott CA, Lund GB, Osterman FA. Intraductal biliary biopsy: comparison of three techniques. J Vasc Interv Radiol 1996; 7(5):743-750

22 Rossi M, Cantisani V, Salvatori FM, et al. Histologic assessment of biliary obstruction with different percutaneous endoluminal techniques. BMC Med Imaging 2004;4(1):3

23 Tapping CR, Byass OR, Cast JE. Cytological sampling versus forceps biopsy during percutaneous transhepatic biliary drainage and analysis of factors predicting success. Cardiovasc Intervent Radiol 2012;35(4):883-889

$24 \mathrm{Kim}$ JY, Choi JH, Kim JH, et al. Clinical usefulness of bile cytology obtained from biliary drainage tube for diagnosing cholangiocarcinoma [in Korean]. Korean J Gastroenterol 2014;63(2):107-113

25 Hemming AW, Reed AI, Howard RJ, et al. Preoperative portal vein embolization for extended hepatectomy. Ann Surg 2003;237(5): 686-691, discussion 691-693

26 Uhl M, Euringer W, Makowiec F, Adam U, Schneider A, Langer M. Portal vein embolization preparation for major hepatic resection: a new standard in liver surgery [in German]. RoFo Fortschr Geb Rontgenstr Nuklearmed 2007;179(1):31-37

27 Galandi D, Schwarzer G, Bassler D, Allgaier HP. Ursodeoxycholic acid and/or antibiotics for prevention of biliary stent occlusion. Cochrane Database Syst Rev 2002;(3):CD003043

28 Davids PH, Groen AK, Rauws EA, Tytgat GN, Huibregtse K. Randomised trial of self-expanding metal stents versus polyethylene stents for distal malignant biliary obstruction. Lancet 1992;340 (8834-8835):1488-1492

29 Kaassis M, Boyer J, Dumas R, et al. Plastic or metal stents for malignant stricture of the common bile duct? Results of a randomized prospective study. Gastrointest Endosc 2003;57(2): 178-182
30 Katsinelos P, Paikos D, Kountouras J, et al. Tannenbaum and metal stents in the palliative treatment of malignant distal bile duct obstruction: a comparative study of patency and cost effectiveness. Surg Endosc 2006;20(10):1587-1593

31 Knyrim K, Wagner HJ, Pausch J, Vakil N. A prospective, randomized, controlled trial of metal stents for malignant obstruction of the common bile duct. Endoscopy 1993;25(3):207-212

32 Soderlund C, Linder S. Covered metal versus plastic stents for malignant common bile duct stenosis: a prospective, randomized, controlled trial. Gastrointest Endosc 2006;63(7):986-995

33 Moss AC, Morris E, Mac Mathuna P. Palliative biliary stents for obstructing pancreatic carcinoma. Cochrane Database Syst Rev 2006;(2):CD004200

34 Mukai T, Yasuda I, Nakashima M, et al. Metallic stents are more efficacious than plastic stents in unresectable malignant hilar biliary strictures: a randomized controlled trial. J Hepatobiliary Pancreat Sci 2013;20(2):214-222

35 Sangchan A, Kongkasame W, Pugkhem A, Jenwitheesuk K, Mairiang P. Efficacy of metal and plastic stents in unresectable complex hilar cholangiocarcinoma: a randomized controlled trial. Gastrointest Endosc 2012;76(1):93-99

36 Loew BJ, Howell DA, Sanders MK, et al. Comparative performance of uncoated, self-expanding metal biliary stents of different designs in 2 diameters: final results of an international multicenter, randomized, controlled trial. Gastrointest Endosc 2009;70(3): 445-453

37 Lammer J, Hausegger KA, Flückiger F, et al. Common bile duct obstruction due to malignancy: treatment with plastic versus metal stents. Radiology 1996;201(1):167-172

38 Isayama H, Kawakubo K, Nakai Y, et al. A novel, fully covered lasercut nitinol stent with antimigration properties for nonresectable distal malignant biliary obstruction: a multicenter feasibility study. Gut Liver 2013;7(6):725-730

39 Kitano M, Yamashita Y, Tanaka K, et al. Covered self-expandable metal stents with an anti-migration system improve patency duration without increased complications compared with uncovered stents for distal biliary obstruction caused by pancreatic carcinoma: a randomized multicenter trial. Am J Gastroenterol 2013;108(11):1713-1722

40 Saleem A, Leggett CL, Murad MH, Baron TH. Meta-analysis of randomized trials comparing the patency of covered and uncovered self-expandable metal stents for palliation of distal malignant bile duct obstruction. Gastrointest Endosc 2011;74(2):321-327.e1, 3

41 Almadi MA, Barkun AN, Martel M. No benefit of covered vs uncovered self-expandable metal stents in patients with malignant distal biliary obstruction: a meta-analysis. Clin Gastroenterol Hepatol 2013;11(1):27-37.e1

42 Kullman E, Frozanpor F, Söderlund C, et al. Covered versus uncovered self-expandable nitinol stents in the palliative treatment of malignant distal biliary obstruction: results from a randomized, multicenter study. Gastrointest Endosc 2010;72(5):915-923

43 Telford JJ, Carr-Locke DL, Baron TH, et al. A randomized trial comparing uncovered and partially covered self-expandable metal stents in the palliation of distal malignant biliary obstruction. Gastrointest Endosc 2010;72(5):907-914

44 Han YM, Jin GY, Lee SO, Kwak HS, Chung GH. Flared polyurethanecovered self-expandable nitinol stent for malignant biliary obstruction. J Vasc Interv Radiol 2003;14(10):1291-1301

45 Hausegger KA, Thurnher S, Bodendörfer G, et al. Treatment of malignant biliary obstruction with polyurethane-covered Wallstents. AJR Am J Roentgenol 1998;170(2):403-408

46 Rossi P, Bezzi M, Salvatori FM, Panzetti C, Rossi M, Pavia G. Clinical experience with covered wallstents for biliary malignancies: 23-month follow-Up. Cardiovasc Intervent Radiol 1997; 20(6):441-447

47 Bezzi M, Zolovkins A, Cantisani V, et al. New ePTFE/FEP-covered stent in the palliative treatment of malignant biliary obstruction. J Vasc Interv Radiol 2002;13(6):581-589 
48 Hatzidakis A, Krokidis M, Kalbakis K, Romanos J, Petrakis I, Gourtsoyiannis N. ePTFE/FEP-covered metallic stents for palliation of malignant biliary disease: can tumor ingrowth be prevented? Cardiovasc Intervent Radiol 2007;30(5):950-958

49 Schoder M, Rossi P, Uflacker R, et al. Malignant biliary obstruction: treatment with ePTFE-FEP-covered endoprostheses initial technical and clinical experiences in a multicenter trial. Radiology 2002;225(1):35-42

50 Santerre JP, Labow RS, Duguay DG, Erfle D, Adams GA. Biodegradation evaluation of polyether and polyester-urethanes with oxidative and hydrolytic enzymes. J Biomed Mater Res 1994; 28(10):1187-1199

51 Mezawa S, Homma H, Sato T, et al. A study of carboplatin-coated tube for the unresectable cholangiocarcinoma. Hepatology 2000; 32(5):916-923

52 Suk KT, Kim JW, Kim HS, et al. Human application of a metallic stent covered with a paclitaxel-incorporated membrane for malignant biliary obstruction: multicenter pilot study. Gastrointest Endosc 2007;66(4):798-803

53 Song TJ, Lee SS, Yun SC, et al. Paclitaxel-eluting covered metal stents versus covered metal stents for distal malignant biliary obstruction: a prospective comparative pilot study. Gastrointest Endosc 2011;73(4):727-733

54 Okuda K, Nakanuma Y, Miyazaki M. Cholangiocarcinoma: recent progress. Part 1: epidemiology and etiology. J Gastroenterol Hepatol 2002;17(10):1049-1055

55 Bismuth $\mathrm{H}$, Corlette MB. Intrahepatic cholangioenteric anastomosis in carcinoma of the hilus of the liver. Surg Gynecol Obstet 1975;140(2):170-178

56 Bismuth $\mathrm{H}$, Castaing D, Traynor O. Resection or palliation: priority of surgery in the treatment of hilar cancer. World J Surg 1988; 12(1):39-47

57 Coons H. Metallic stents for the treatment of biliary obstruction: a report of 100 cases. Cardiovasc Intervent Radiol 1992;15(6): 367-374

58 Adam A. Metallic biliary endoprostheses. Cardiovasc Intervent Radiol 1994;17(3):127-132

59 Cowling MG, Adam AN. Internal stenting in malignant biliary obstruction. World J Surg 2001;25(3):355-359, discussion 359361

60 Inal M, Akgül E, Aksungur E, Seydaoğlu G. Percutaneous placement of biliary metallic stents in patients with malignant hilar obstruction: unilobar versus bilobar drainage. J Vasc Interv Radiol 2003;14(11):1409-1416

61 Chang WH, Kortan P, Haber GB. Outcome in patients with bifurcation tumors who undergo unilateral versus bilateral hepatic duct drainage. Gastrointest Endosc 1998;47(5): 354-362

62 Naitoh I, Hayashi K, Nakazawa T, et al. Side-by-side versus stentin-stent deployment in bilateral endoscopic metal stenting for malignant hilar biliary obstruction. Dig Dis Sci 2012;57(12): 3279-3285

63 Kim CW, Park AW, Won JW, Kim S, Lee JW, Lee SH. T-configured dual stent placement in malignant biliary hilar duct obstructions with a newly designed stent. J Vasc Interv Radiol 2004;15(7): 713-717

64 Gwon DI, Ko GY, Yoon HK, et al. Safety and efficacy of percutaneous Y-configured covered stent placement for malignant hilar biliary obstruction: a prospective, pilot study. J Vasc Interv Radiol 2012;23(4):528-534

65 Yun JH, Jung GS, Park JG, et al. Malignant hilar biliary obstruction: Treatment by means of placement of a newly designed Y-shaped branched covered stent. Cardiovasc Intervent Radiol 2016;39(4): 582-590

66 Corvino F, Centore L, Soreca E, Corvino A, Farbo V, Bencivenga A. Percutaneous "Y" biliary stent placement in palliative treatment of type 4 malignant hilar stricture. J Gastrointest Oncol 2016;7(2): 255-261
67 Bae JI, Park AW, Choi SJ, et al. Crisscross-configured dual stent placement for trisectoral drainage in patients with advanced biliary hilar malignancies. J Vasc Interv Radiol 2008;19(11): 1614-1619

68 Bruha R, Petrtyl J, Kubecova M, et al. Intraluminal brachytherapy and selfexpandable stents in nonresectable biliary malignanciesthe question of long-term palliation. Hepatogastroenterology 2001;48(39):631-637

69 Fritz P, Brambs HJ, Schraube P, Freund U, Berns C, Wannenmacher $M$. Combined external beam radiotherapy and intraluminal high dose rate brachytherapy on bile duct carcinomas. Int J Radiat Oncol Biol Phys 1994;29(4):855-861

70 Aggarwal R, Patel FD, Kapoor R, Kang M, Kumar P, Chander Sharma S. Evaluation of high-dose-rate intraluminal brachytherapy by percutaneous transhepatic biliary drainage in the palliative management of malignant biliary obstruction-a pilot study. Brachytherapy 2013;12(2):162-170

71 Kocak Z, Ozkan H, Adli M, Garipagaoglu M, Kurtman C, Cakmak A. Intraluminal brachytherapy with metallic stenting in the palliative treatment of malignant obstruction of the bile duct. Radiat Med 2005;23(3):200-207

72 Eschelman DJ, Shapiro MJ, Bonn J, et al. Malignant biliary duct obstruction: long-term experience with Gianturco stents and combined-modality radiation therapy. Radiology 1996;200(3): 717-724

73 Takamura A, Saito H, Kamada T, et al. Intraluminal low-dose-rate 192Ir brachytherapy combined with external beam radiotherapy and biliary stenting for unresectable extrahepatic bile duct carcinoma. Int J Radiat Oncol Biol Phys 2003;57(5):1357-1365

74 Isayama H, Tsujino T, Nakai Y, et al. Clinical benefit of radiation therapy and metallic stenting for unresectable hilar cholangiocarcinoma. World J Gastroenterol 2012;18(19):2364-2370

75 Shin HS, Seong J, Kim WC, et al. Combination of external beam irradiation and high-dose-rate intraluminal brachytherapy for inoperable carcinoma of the extrahepatic bile ducts. Int J Radiat Oncol Biol Phys 2003;57(1):105-112

76 Cho YK, Kim JK, Kim MY, Rhim H, Han JK. Systematic review of randomized trials for hepatocellular carcinoma treated with percutaneous ablation therapies. Hepatology 2009;49(2): 453-459

77 Mulier S, Ruers T, Jamart J, Michel L, Marchal G, Ni Y. Radiofrequency ablation versus resection for resectable colorectal liver metastases: time for a randomized trial? An update. Dig Surg 2008;25(6):445-460

78 Sutherland LM, Williams JA, Padbury RT, Gotley DC, Stokes B, Maddern GJ. Radiofrequency ablation of liver tumors: a systematic review. Arch Surg 2006;141(2):181-190

79 Zacharoulis D, Lazoura O, Sioka E, et al. Habib EndoHPB: a novel endobiliary radiofrequency ablation device. An experimental study. J Invest Surg 2013;26(1):6-10

80 Itoi T, Isayama H, Sofuni A, et al. Evaluation of effects of a novel endoscopically applied radiofrequency ablation biliary catheter using an ex-vivo pig liver. J Hepatobiliary Pancreat Sci 2012;19(5): 543-547

81 Steel AW, Postgate AJ, Khorsandi S, et al. Endoscopically applied radiofrequency ablation appears to be safe in the treatment of malignant biliary obstruction. Gastrointest Endosc 2011;73(1): 149-153

82 Mizandari M, Pai M, Xi F, et al. Percutaneous intraductal radiofrequency ablation is a safe treatment for malignant biliary obstruction: feasibility and early results. Cardiovasc Intervent Radiol 2013;36(3):814-819

83 Li TF, Huang GH, Li Z, et al. Percutaneous transhepatic cholangiography and intraductal radiofrequency ablation combined with biliary stent placement for malignant biliary obstruction. J Vasc Interv Radiol 2015;26(5):715-721

84 Wang J, Zhao L, Zhou C, et al. Percutaneous intraductal radiofrequency ablation combined with biliary stent placement 
for nonresectable malignant biliary obstruction improves stent patency but not survival. Medicine (Baltimore) 2016; 95(15):e3329

85 Pai M, Valek V, Tomas A, et al. Percutaneous intraductal radiofrequency ablation for clearance of occluded metal stent in malignant biliary obstruction: feasibility and early results. Cardiovasc Intervent Radiol 2014;37(1):235-240

86 Duan XH, Wang YL, Han XW, et al. Intraductal radiofrequency ablation followed by locoregional tumor treatments for treating occluded biliary stents in non-resectable malignant biliary obstruction: A single-institution experience. PLoS One 2015: 10(8):e0134857

87 McCaughan JS Jr, Mertens BF, Cho C, Barabash RD, Payton HW. Photodynamic therapy to treat tumors of the extrahepatic biliary ducts. A case report. Arch Surg 1991;126(1):111-113
88 Abels C. Targeting of the vascular system of solid tumours by photodynamic therapy (PDT). Photochem Photobiol Sci 2004; 3(8):765-771

89 Castano AP, Mroz P, Hamblin MR. Photodynamic therapy and antitumour immunity. Nat Rev Cancer 2006;6(7):535-545

90 Ortner MA. Photodynamic therapy for cholangiocarcinoma: overview and new developments. Curr Opin Gastroenterol 2009; 25(5):472-476

91 Leggett CL, Gorospe EC, Murad MH, Montori VM, Baron TH, Wang KK. Photodynamic therapy for unresectable cholangiocarcinoma: a comparative effectiveness systematic review and meta-analyses. Photodiagn Photodyn Ther 2012;9(3):189-195

92 Lu Y, Liu L, Wu JC, Bie LK, Gong B. Efficacy and safety of photodynamic therapy for unresectable cholangiocarcinoma: A metaanalysis. Clin Res Hepatol Gastroenterol 2015;39(6):718-724 